\title{
Some of the atmospheric influences on microwave propagation through atmosphere
}

\author{
P.K.Karmakar*, Lahari Sengupta, M. Maiti and Carlos Frederico Angelis ${ }^{1}$ \\ Centre for Research and Training in Microwaves and Millimeterwaves \\ Institute of Radiophysics and Electronics, University of Calcutta, \\ 92 A.P.C Road. Kolkata 700 009, India \\ ${ }^{1}$ Instituto Nacional de Pesquisas Espaciais (INPE), Centro de Previsão de Tempo e Estudos \\ Climáticos (CPTEC), National Institute for Space Research \\ Center for Weather Forecast and Climate Studies \\ Rodovia Pres. Dutra, km 40, Cachoeira Paulista /SP - 12630-000 Brazil
}

\begin{abstract}
Amongst the suspended particles in the atmosphere, water vapor and fog are the most influencing parameters when microwave propagates through the atmosphere. Attenuation due to these along with rain are considered in detail, over Kolkata $\left(22^{\circ} \mathrm{N}\right)$, India and Cachoeira Paulista $\left(22^{0} \mathrm{~S}\right)$, Brazil. Rain, perhaps is considered to be the worst offender in microwave propagation. The rain patterns over Kolkata, Brazil and U.K are compared and hence the attenuation also.
\end{abstract}

Keywords: Microwaves, water vapor, fog, rain attenuations.

\section{INTRODUCTION}

The pressing need for developing the variety of communication system pushes the scientists and engineers to explore for the potential use of the microwave and millimeter wave band of the electromagnetic spectrum. The most important advantages of implementing miniaturized microwave systems are the availability of more directive antenna gain and large bandwidth. At such high frequencies, for example, $1 \%$ bandwidth at 600 $\mathrm{MHz}$ is $6 \mathrm{MHz}$ (the band width of single television channel) and at $60 \mathrm{GHz}, 1 \%$ bandwidth is 600 $\mathrm{MHz}$ (100 television channel). But, on the other hand, at frequencies above about $10 \mathrm{GHz}$, electromagnetic radiation starts interacting with the neutral atmosphere and also with the various meteorological parameters, in particular, precipitation, producing absorption of energy, and thus attenuation of signal levels. Implicit in these predictions of losses is a detailed knowledge of the physical mechanism of the various meteorological parameters, and their interactions with electromagnetic radiation.

The adverse weather causes microwave signal degradations mostly due to rain and suspended particles like fog and water vapor. Atmospheric gases cause signal attenuation through molecular absorption in certain characteristic frequency bands.

A very large number of gases exhibit resonant absorption features. But, only a few have a major impact on signal propagation through the earth's atmosphere in the wavelength range of interest. Molecular oxygen and water vapor at millimeter \& sub millimeter wavelengths are the most important constituents.

The purpose of the present work initially is to find out the different types of losses to be incurred at the conventional window frequencies i.e., 30 and 94 $\mathrm{GHz}$ along with the losses at the first and weak water vapor resonance line i.e., around $22 \mathrm{GHz}$ in the microwave/millimeter wave band. For this purpose, taking the advantages of latitudinal occupancy, we have used the radiosonde data available over Kolkata $\left(22^{\circ} \mathrm{N}\right)$, India and Rio-deJaneiro $\left(22^{\circ} \mathrm{S}\right)$, Brazil, from British Atmospheric Data Center (BADC), U.K.

Water vapor attenuation: In addition to absorption by molecular oxygen, molecules of water vapor also interact with electromagnetic radiation in the 
microwave and millimeter wave regions. The water vapor molecule being a permanent electric dipole produces rotational transitions of the order of $10^{4}$ times stronger than that of the magnetic transitions of the oxygen molecule. So, even though the abundance of water vapor in the atmosphere is considerably less than that of oxygen, it can produce significant (and intense) level of attenuation near the resonant frequencies.

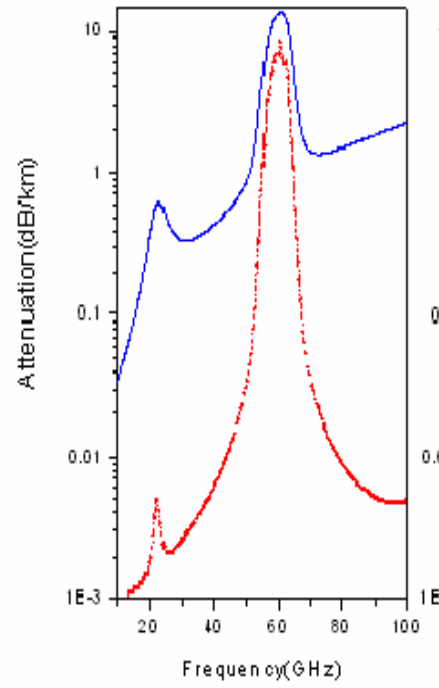

(a)

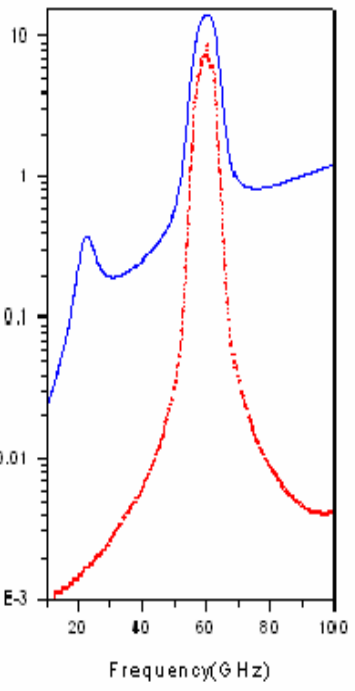

(b)
Surface values on $1^{\text {st }}$ July '09 morning.

$10 \mathrm{~km}$ height above surface on $1^{\text {st }}$ July '09 morning.

Fig 1: Comparison of attenuation at microwave frequencies over Kolkata and Rio-de-Janeiro. where (a) is for Kolkata $\left(22^{0} \mathrm{~N}\right)$ and (b) is for Rio-de-Janeiro (22 S)

Water vapor attenuation is found to depend quadratically on water vapor density, particularly at high densities, above about $12 \mathrm{~g} / \mathrm{m}^{3}$.

Amongst all the well-documented attributes of millimeter waves is their decisive advantage over infrared and optical waves when obscuration effects due to suspended atmospheric particles impose serious restriction on system performance. For the potential benefits of operating in the region 10-100 $\mathrm{GHz}$, the system designers have to rely on the realistic atmospheric propagation models capable of predicting attenuation by water vapor, fog, haze and rainy as well.

The propagation effects other than rain can be evaluated by specifying four input parameters: frequency in $\mathrm{GHz}$, total pressure in $\mathrm{kPa}$, temperature in ${ }^{\circ} \mathrm{C}$ and relative humidity in $\%$ by using MPM model (Liebe, 1989). Fig 1 represents the total attenuation (excluding rain effect) versus frequency plots over Kolkata $\left(22^{0} \mathrm{~N}\right)$, India and the other one for Rio-de-Janeiro $\left(22^{0} \mathrm{~S}\right)$, Brazil, on $1^{\text {st }}$ July 2009 during morning hours. It is noted that at Kolkata and Rio-deJaneiro, the weak resonant line is present at 22.234 $\mathrm{GHz}$ at surface. The corresponding peak attenuation at Kolkata is $0.6 \mathrm{~dB} / \mathrm{km}$ but at Rio-de-Janeiro it is 0.3 $\mathrm{dB} / \mathrm{km}$. The next maxima are at $60 \mathrm{GHz}$ for both the places and each of them suffers an attenuation of 10 $\mathrm{dB} / \mathrm{km}$. But in case of $10 \mathrm{~km}$ height from surface, at Kolkata, a resonant line at $22.234 \mathrm{GHz}$ with $0.005 \mathrm{~dB} / \mathrm{km}$ attenuation is prominent. But on the other hand, the absence of this line is prominent at Rio-de-Janeiro. The reason behind the absence of the 22.234 GHz resonant line at Rio-de-Janeiro, Brazil at $10 \mathrm{~km}$ height may be due to the fact that no or very little transportation of water vapour from the surface takes place at that height over Rio-de-Janeiro although the present authors in separate communications have shown that the integrated water vapor content over Brazil, during morning hours is about $40 \mathrm{~kg} \mathrm{~m}^{-2}$ (Karmakar et al 2010 ) and that over Kolkata this value goes upto $60 \mathrm{~kg} \mathrm{~m}^{-2}$ ( Karmakar et al 1994). In another paper one of the present authors (Sen et al 1989) concluded that any transportation of water vapour from the surface to the higher altitudes have been negligible effect within 12-24 hours time scale. If the time scale is increased to $48 \mathrm{hrs}$, the integrated water vapour content is poorly correlated with that around $2 \mathrm{~km}$ height which happens to be the scale height over Brazil (Karmakar et al 2010). The difference in behavior in this type of variation for a short (12-24 hours) and a long time of $48 \mathrm{hrs}$ scale suggests that the transportation of water vapour to high altitudes occurred within a time scale greater than 24 hours. In other words, we can say that most of the water vapor over Brazil remain within the troposphere. The Clausius-Clapeyron relation establishes that air can hold more water when it warms. This and other basic principles indicate that warming associated with increased concentrations of the other green house gases also will increases the concentration of water vapour. This suggests that in the morning spell the place of choice at Brazil is cooler than that at Kolkata.

Since water vapor is a green house gas and because warm air can hold more water vapour than cooler air, this amplifies the original warming due to water vapour.

Another important consideration is that the water vapour being the only green house gas whose 
Am. J. Sci. Ind. Res., 2010, 1(2): 350-358

concentration is highly variable in space and time in the atmosphere, its real time measurement is highly emerging topic of research interest to be persuaded in different locations all over the globe. The IPCC fourth assessment report (Cracknell et al 2007) says that a further warming of about $0.1^{\circ} \mathrm{C}$ per decade would be expected even if the concentration of all green house gases and aerosols had been kept constant. This report also says that in order to reduce the level of existing uncertainties, the modeling of nature society interaction is urgently required on a long term basis taking into account non linear changes in climate systems.

Attenuation due to fog: Fog can be formed in variety of ways depending mostly on the condensation mechanism. Generally, we encounter the type of fog, which is formed by the cooling of land after sunset by thermal radiation in calm and clear sky. The cool ground produces condensation in the nearby area by conduction of heat. This type of fog mostly prevails at night and does not last long after sunrise. It generally occurs in autumn and winter.

Fog attenuation is comparatively smaller at millimeter wavelength. Fog is composed of suspended spherical water droplets with radii small enough to keep them suspended in air by micro turbulence (Liebe et. al., 1989). Attenuation due to fog in the millimeter wave band is mainly caused by absorption and scattering which in turn depends on the extent of the fog density (in other words visibility) and its index of refraction. According to Gibbins (1988), the fog density is given in terms of visibility $V(\mathrm{~km})$ by

$$
M=\left(\frac{0.024}{V}\right)^{1.54} \mathrm{gm}^{-3}
$$

Fig. (2) shows the variation of extent of the fog in terms of density. However, it is to be remembered here, that, we are concerned with the radiation fog for which the fog density approaches nearly $1 \mathrm{gm} / \mathrm{m}^{3}$. But over U.K.(non-tropical zone), Gibbins (1988) pointed out that fog occurs typically of the order of $1-2 \%$ of the time over a period of one year. The density of this type of fog is $0.02 \mathrm{gm} / \mathrm{m}^{3}$ for which the visibility is 300 $\mathrm{m}$ and is termed as moderate fog.

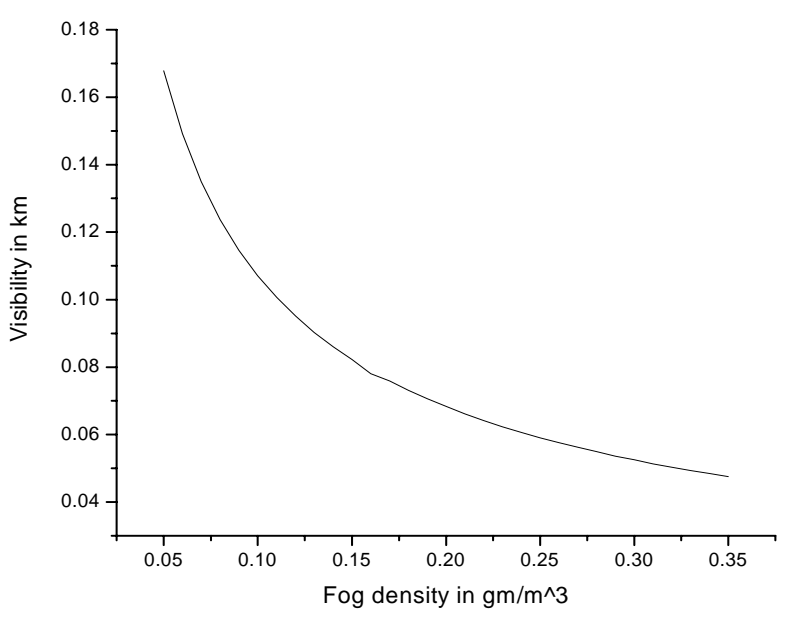

Fig 2: Fog density versus visibility characteristics.

Comparing the size of the suspended water droplets (fog) and the wavelength in the millimeter wave band, the Rayleigh approximation may be adopted for defining the refractivity model. Using the Rayleigh absorption approximation (Van de Hulst, 1957), refractivity is written as

$$
N=M\left(3 / 2 m_{w}\right)(\varepsilon-1) /(\varepsilon+2) \mathrm{ppm}
$$

Where, $m_{w}=$ specific weight for water $=1.0$

and $M$ is defined as given in equation (1) and is the complex permittivity.

According to Liebe et al (1989) we define the power loss of the radio wave while propagating through fog as

$$
\left.\alpha=0.182 f N^{\prime \prime}(f) \mathrm{dB} / \mathrm{km} \quad 3\right)
$$

where $N^{\prime \prime}(f)$ is complex refractivity.

An attempt has been made to describe the fog attenuation at 30 and $94 \mathrm{GHz}$ considering temperatures as the parameters ranging from $284 \mathrm{~K}$ to $303 \mathrm{~K}$. This is pictorially present in Fig. (3). It is clear from the figure that within the said temperature range, the $30 \mathrm{GHz}$ attenuation never exceeds 0.35 $\mathrm{dB} / \mathrm{km}$. But on the other hand, the $94 \mathrm{GHz}$ attenuation shows, for the same range of temperatures and for fog densities $0.5 \mathrm{gm} / \mathrm{m}^{3}$, its value ranges from 2.1029 to $1.6283 \mathrm{~dB} / \mathrm{km}$. For the sake of clarity, it is also observed that for $0.5 \mathrm{gm} / \mathrm{m}^{3}$ and for temperature $284.7 \mathrm{~K}$ the $94 \mathrm{GHz}$ attenuation is more or less 7 times larger than that at $30 \mathrm{GHz}$. This ratio becomes very much pertinent to our study 
because we are concerned with the radiation fog whose density mostly approaches towards 0.3-0.7 $\mathrm{gm} / \mathrm{m}^{3}$. But, in case of the advection fog; its density is less (nearly equal to $0.2 \mathrm{gm} / \mathrm{m}^{3}$ ) and hence this attenuation ratio is not that much prominent to be noticed in microwave propagation.

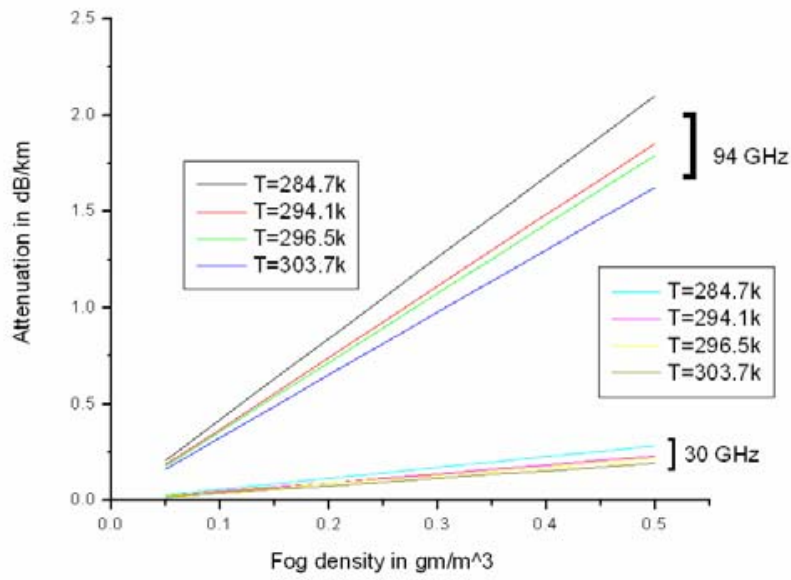

Fig 3: Fog density versus attenuation curve.

To exemplify the dependence of temperature on fog attenuation at 30 and $94 \mathrm{GHz}$, Fig 4 has been presented keeping fog density equals to $0.5 \mathrm{gm} / \mathrm{m}^{3}$.

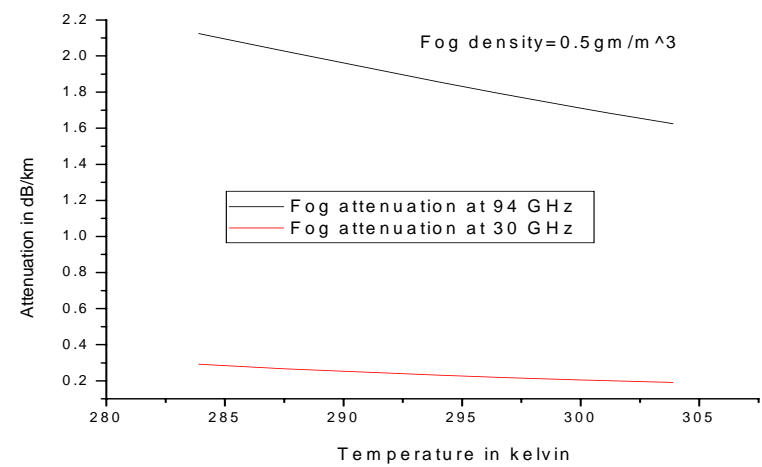

Fig 4: Temperature versus attenuation curve.

\section{ESTIMATION OF RAIN}

The rain rate profiles during 1985-86 were recorded at the Institute of Radio Physics and Electronics, University of Calcuttta, using a 'Dynabab' fast response rain gauge having response time $10 \mathrm{~s}$. A statistics of the peak rain rate during the said period is shown in Fig (5). (Karmakar, 1990) This is comparable to a similar histogram for longer period of four years obtained from the measured rain rates at U.K. (Norbury and white, 1975) as shown in Fig (5).
The distribution of duration of the rain events at Kolkata and U.K. are shown in Fig (6). This shows a similar trend in the order of the values except few cases of very high rain rates occurring in Kolkata (a tropical zone).

The total number of rain events with rain rates exceeding $25 \mathrm{~mm} / \mathrm{hr}$ is 85 measured at Kolkata in 1986, while in U.K. the total number is only 77 for rain rates exceeding $20 \mathrm{~mm} / \mathrm{hr}$ measured over four years (1970-73). This exhibits only the great abundances of large rain events in the tropical station like Kolkata, relative to that at U.K.

The rainfall intensity data and the corresponding rain attenuation data for the year 2009 over Cachoeira Paulista (22 deg South), Brazil, is also provided by the precipitation monitor.

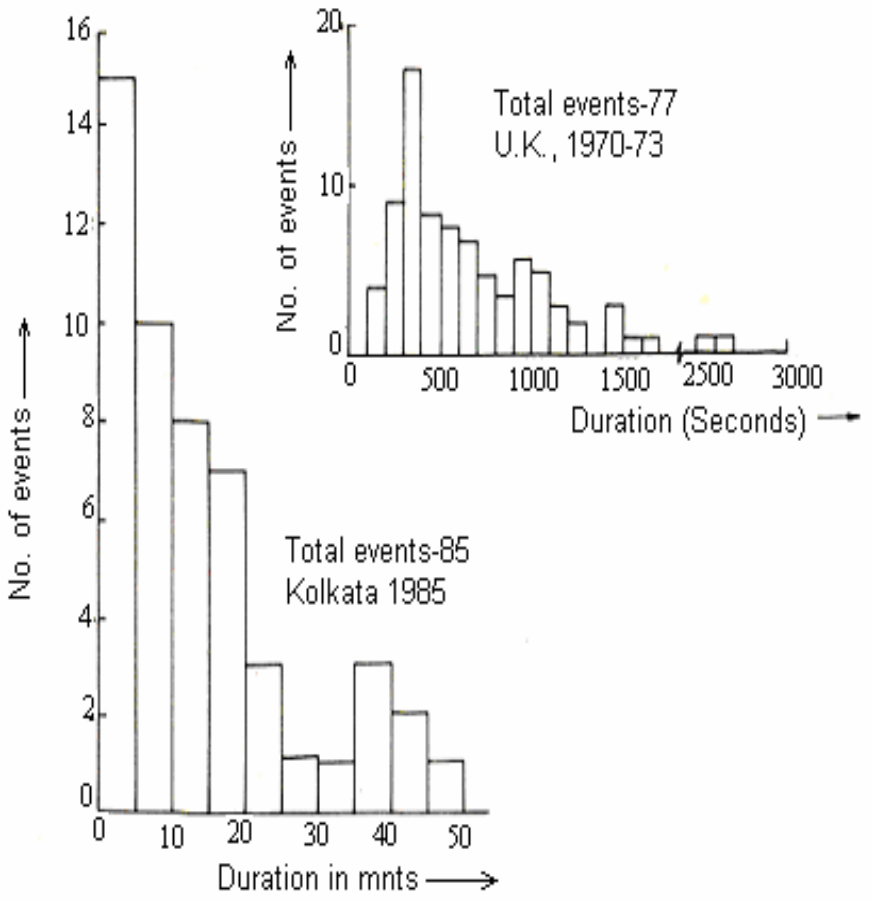

Fig 5: statistics of peak rain rate over Kolkata (1985) and that over U.K. (1970-73). Similarly of these two histograms exhibited.

The rain monitor has the capability of measuring maximum rain rate upto $250 \mathrm{~mm} / \mathrm{hr}$ and a minimum upto $0.0005 \mathrm{~mm} / \mathrm{hr}$ with a resolution time 10 secs. 


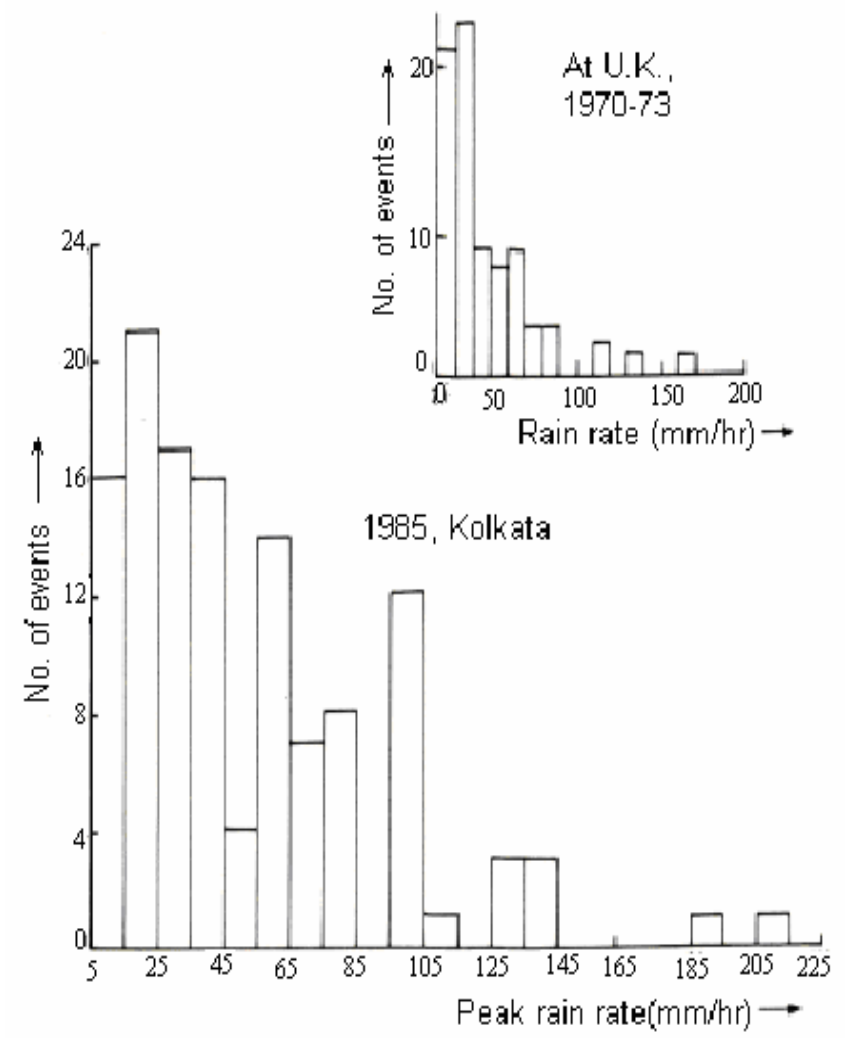

Fig 6: Histogram of duration of rain events over Kolkata and that over U.K. Histogram shows the same nature.

Rain fall rate at Cachoeira Paulista $\left(22^{\circ} \mathrm{S}\right)$, Brazil were measured during Dec, 2008 till July, 2009. It is noted that heavy rainfall is largely restricted to late afternoon or in the evening hours. Although there are no dry spells as such, the rainy season over Brazil is normally considered to be the period between December and May. However April is the wettest month. The dominant rain forming mechanism in this region is due to convective activity. It is interesting to note that rain rate rarely goes beyond $100 \mathrm{~mm} / \mathrm{hr}$ during our study. There were few events occurred when rain rates attain a maximum value of 107 $\mathrm{mm} / \mathrm{hr}$. A statistical analysis of the number of rain events over Cachoeira Paulista(CP, $\left.22^{\circ} \mathrm{S}\right)$, Brazil during the year 2009, reveals that the number of occurrence goes beyond 200 for rain rate upto 15 $\mathrm{mm} / \mathrm{hr}$ but quite interestingly it is observed that the number of events goes well below75 for the rain rates ranging from 15 to $25 \mathrm{~mm} / \mathrm{hr}$. And subsequently the number of events for the higher rain rates takes a sequential step down reaching ultimately to highest rain rates $107 \mathrm{~mm} / \mathrm{hr}$. Eventually, this distribution represents a log-normal distribution over CP, Brazil. But on the other hand the rain rate distribution over Kolkata $\left(22^{0} \mathrm{~N}\right)$, India, strikingly revealed that the normal distribution is well fitted with the measured data. In case of log-normal distribution, it was found by Chi-square test that probability lies between 0.30 to 0.50 , whereas in case of normal fitting it was observed that the probability lies between 0.85 and 0.75 and it was also found that only $12 \%$ is the probability of the raining beyond $50 \mathrm{~mm} / \mathrm{hr}$. The same procedure has been adopted to find out the probability of raining at around $50 \mathrm{~mm} / \mathrm{hr}$ over $\mathrm{CP}$, Brazil and is found to be about $20 \%$. However, the occurrence of the rain events at Brazil is presented in Fig (7).

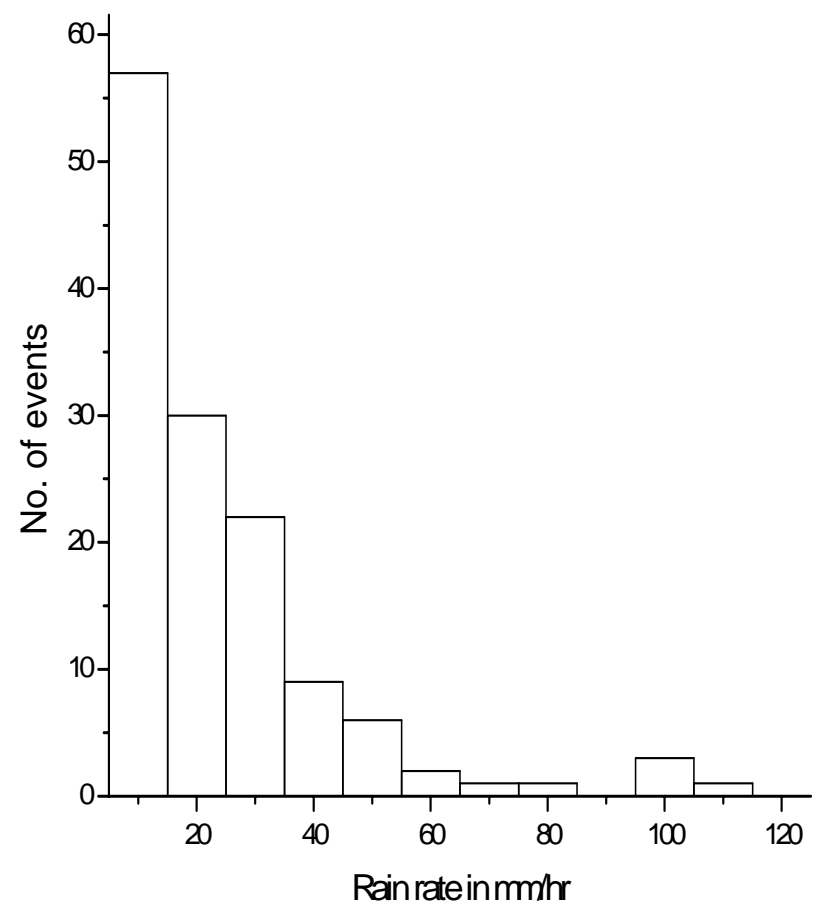

Fig 7: Histogram of rain rate over Cachoeira Paulista $\left(22^{0} \mathrm{~S}\right)$, Brazil

A cumulative distribution of the rain rate has been presented in Fig (8) from the data obtained by the fast response rain gauge located at the Institute of Radio Physics and Electronics, Kolkata, India. It is shown by the continuous line curve as shown in Fig (8). Two other curves have also been included for comparison. The broken line curve is an average 
curve of 5 minute rain rate averaged over a period of 1979-83 (Sinha et. al., 1987) based on data obtained at kolkata using ordinary tipping bucket rain gauges. The dashed curve in Fig (8) shows a clock minute surface rainfall rates for CCIR rain climate region 1 , which actually include India (CCIR 1974).

The curves are in close agreement except the curve for the year 1985, extends up to about $240 \mathrm{~mm} / \mathrm{hr}$ which again shows a large abundance of rain fall in Kolkata, while the other two show higher occurrence of rain fall rate above about $80 \mathrm{~mm} / \mathrm{hr}$.

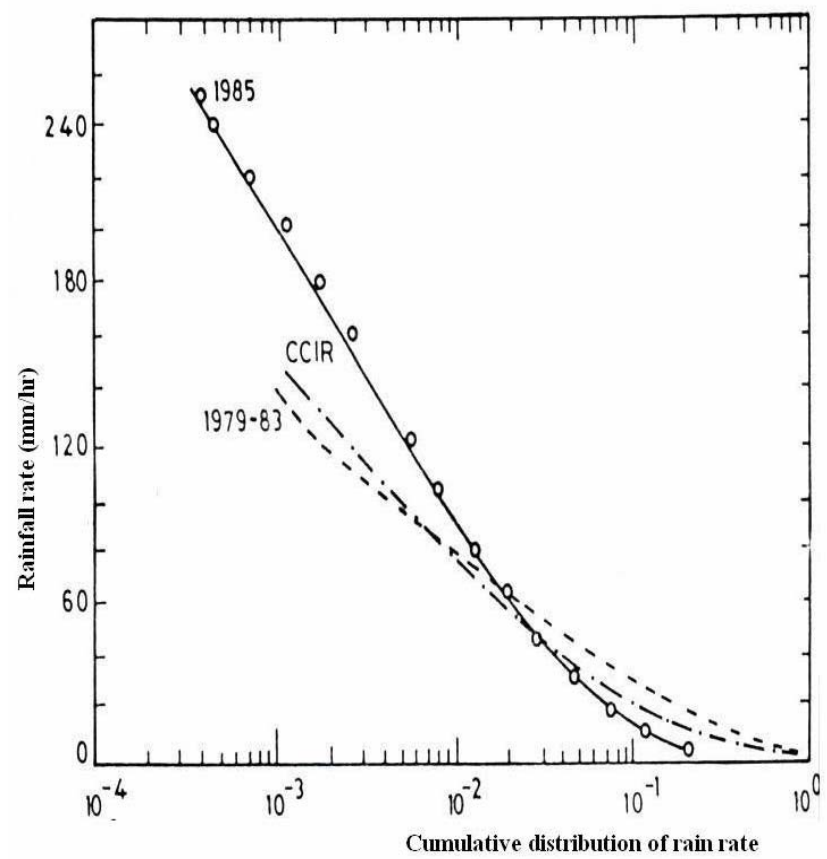

Fig 8: Percent of time rainfall rate exceeded ordinate.

\section{RAIN ATTENUATION}

At frequencies above $10 \mathrm{GHz}$ electromagnetic radiation starts interacting with the neutral atmosphere and with various meteorological parameters, in particular, with the precipitation. Moreover, water droplets present in the radio path act as an imperfect conductor. Hence millimeter waves after interfacing with them cause a displacement current which is directly proportional to the frequency of the wave. Therefore, the attenuation due to the presence of water droplets in the propagation path varies as wave frequency. However rain attenuation and scattering by rain primarily depends on shape, size and the complex dielectric constants of the drops, and on the wavelength and polarization of the incident electromagnetic wave. For spherical droplets, the theory of absorption and scattering was formulated by Mie's theory (1908) and afterwards for the non-spherical droplets, it was formulated by Oguchi and Hosoya (1974). In fact, rain attenuation is characterized by non-uniformity of rain fall intensity, rain drop number density, rain drop temperature in addition to its intrinsic variability in time and space.

The most commonly used raindrop sizes were given by Laws and Parsons (1943), Marshall and Pamer (1948), Joss et. al. (1968). For practical applications, however the relation between the rain rate and specific attenuation for a number of rain drop size distributions is approximated to simple power law (Fedi, 1979) in the form of

$\alpha=a R^{b} \mathrm{~dB} / \mathrm{km}$.

However, to deduce the rain attenuation statistics from the rain rate data, as a first step equation (4) has been used. Assuming Laws and Parsons Distribution of raindrop Hardens et. al. (1978) estimated theoretically the values of $a$ and $b$ from which the values of the parameters for $10,12,18,22$, $30,35,40,53,94$ and $100 \mathrm{GHz}$ were obtained by interpolation, (refer to table 2). Now, the rain attenuations have been calculated for different rain rates, considering Laws and Parsons drop size distribution and shown in Fig (9).

$\underline{\text { Table } 2}$

\begin{tabular}{|l|l|l|}
\hline Frequency & $\begin{array}{l}\text { Vertical } \\
\text { polarization (a) }\end{array}$ & $\begin{array}{l}\text { Vertical } \\
\text { polarization (b) }\end{array}$ \\
\hline 11 & 0.012 & 1.23 \\
\hline 18 & 0.053 & 1.07 \\
\hline 24 & 0.10 & 1.03 \\
\hline 30 & 0.17 & 0.98 \\
\hline 40 & 0.31 & 0.91 \\
\hline 60 & 0.63 & 0.81 \\
\hline 80 & 0.86 & 0.76 \\
\hline 100 & 1.06 & 0.73 \\
\hline
\end{tabular}




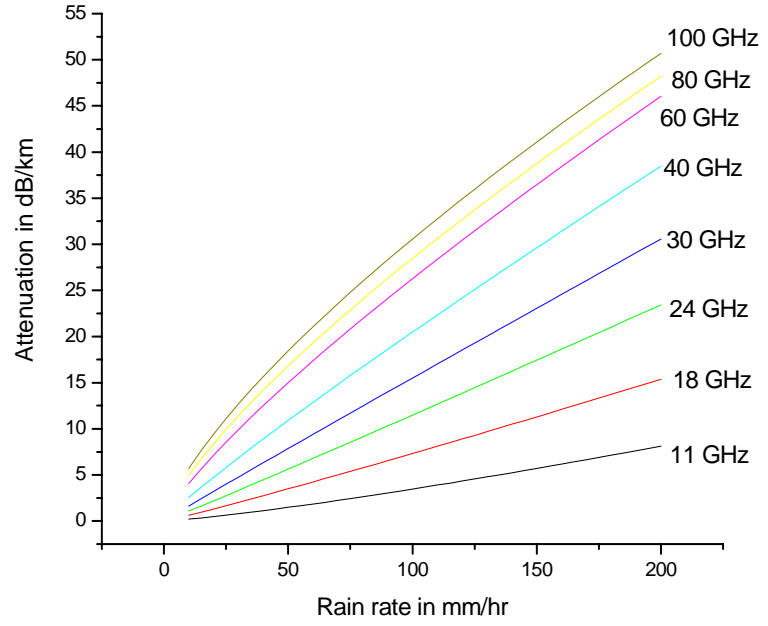

Fig 9: Predicted rain attenuation assuming Laws and Parsons Distribution.

From this curves it was noticed that all curves increase linearly irrespective of frequencies. But the radiometric measurements show that rain attenuation curves become saturated after a certain rain rate. This was also observed that as we move towards the higher frequency, the saturation evolves at a lesser rain rate. To clarify the situation we have initially started measuring rain attenuation by multi-channel microwave radiometer installed at Cachoeira Paulista ,Brazil $\left(22^{\circ} \mathrm{S}\right)$.

Rain attenuations have been measured from the brightness temperature available from the multi channel zenith looking microwave radiometer. The rain attenuation were calculated by using the relation

$A(d B)=10 \log _{10} \frac{T_{m}-T_{c}}{T_{m}-T_{b}}$

Where $T_{m}$ is the mean atmospheric temperature in Kelvin $=290 \mathrm{~K}$

$T_{c}$ is the cosmic background noise temperature in Kelvin $=3 \mathrm{~K}$

$T_{b}$ is the measured brightness temperature in Kelvin

For tropical locations like Kolkata, India $\left(22^{\circ} \mathrm{N}\right)$, \& Cachoeira Paulista ,Brazil $\left(22^{\circ} \mathrm{S}\right)$, the value of $\mathrm{T}_{\mathrm{m}}$ will be higher than those in temperate latitudes due to higher temperatures and large water vapour content. The cumulative distributions for the signal attenuation at different frequencies over $\mathrm{CP}$, Brazil have been studied.

Figure 10 shows the cumulative distribution of measured rain rate for the year 2009 over Cachoeira Paulista $\left(22^{\circ} \mathrm{S}\right)$, Brazil, when compared with ITU-R (2003) recommendation, the experimental results show approximately good agreement at lower rain rates. This prediction model was reported to agree well for temperate regions where the rain structure is considered to be stratiform in nature. But the two distributions show a monotonous decrease in rain rate. The difference between measured and standard prediction model is the existence of "break point" in the exceedence curve. The presence of such break point in the exceedance curve was reported by several authors (Pan et al., 1994; Ramchandran and Kumar, 2007; Mandeep and Allnutt, 2007). The break point here refers to the point at which the trend gets reversed (Kumar et al., 2006; Bryant et al., 2001). The break point of rain rate observed approximately at 8 and $76 \mathrm{~mm} / \mathrm{hr}$. over $\mathrm{CP}$. When the rain structure is stratiform, the rainfall is widespread, with low rain rates (Mandeep and Allnutt, 2007). But at $76 \mathrm{~mm} / \mathrm{hr}$ there occurs another break point. This usually occurs in the tropics. When the cloud builds up, the water droplets are trapped in updrafts inside the cloud and are vertically transported. This enhances the coalescence of water particles resulting in convective heavy rain (Flavin, 1982). Hence, there lies the probability that at the breakpoint either the rain structure changes or it happens due to the changes in cloud morphology.

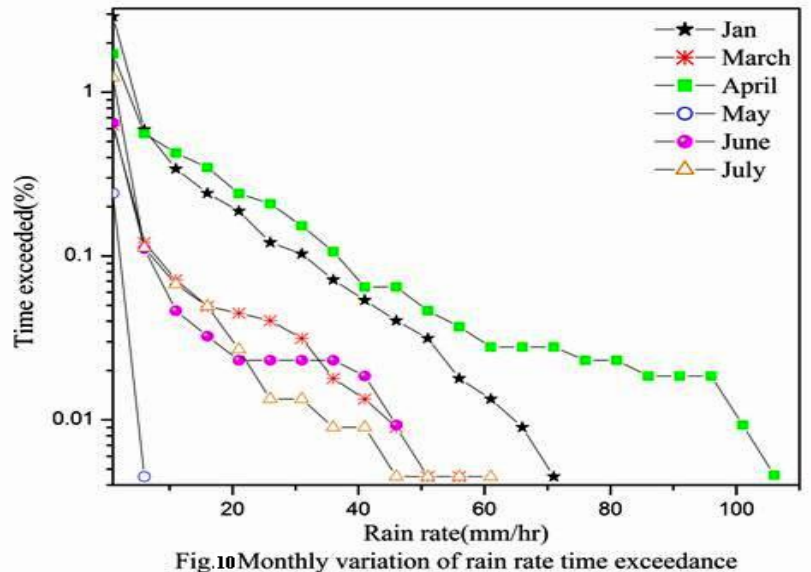

The rain attenuation $(\mathrm{dB})$ exceedence also show the breakpoints for some frequencies around the water vapour band. (Fig.11). There exists a good similarity in nature between rain rate and attenuation breakpoint. The measured attenuation exceedance at 
Am. J. Sci. Ind. Res., 2010, 1(2): 350-358

different frequencies around the said band have been compared with the world standard prediction models ITU-R P.618-8 (ITU-R P.618-8, 2003.) and Ramchandran \& Kumar model (Ramchandran \& Kumar, 2007).

It has been observed that measured result is very close to ITU-R model except the existence of breakpoint. The reason behind this may be due to the fact that these models are applicable for temperate region where rain rate is low and rain height is considered to be more or less constant. The ITU-R model includes a few rain zones which is not accommodating the wide range of rain conditions in the tropical zone. Hence, a detailed and large data bank has to be formed over a tropical region to make the idea of existence of breakpoint clear.
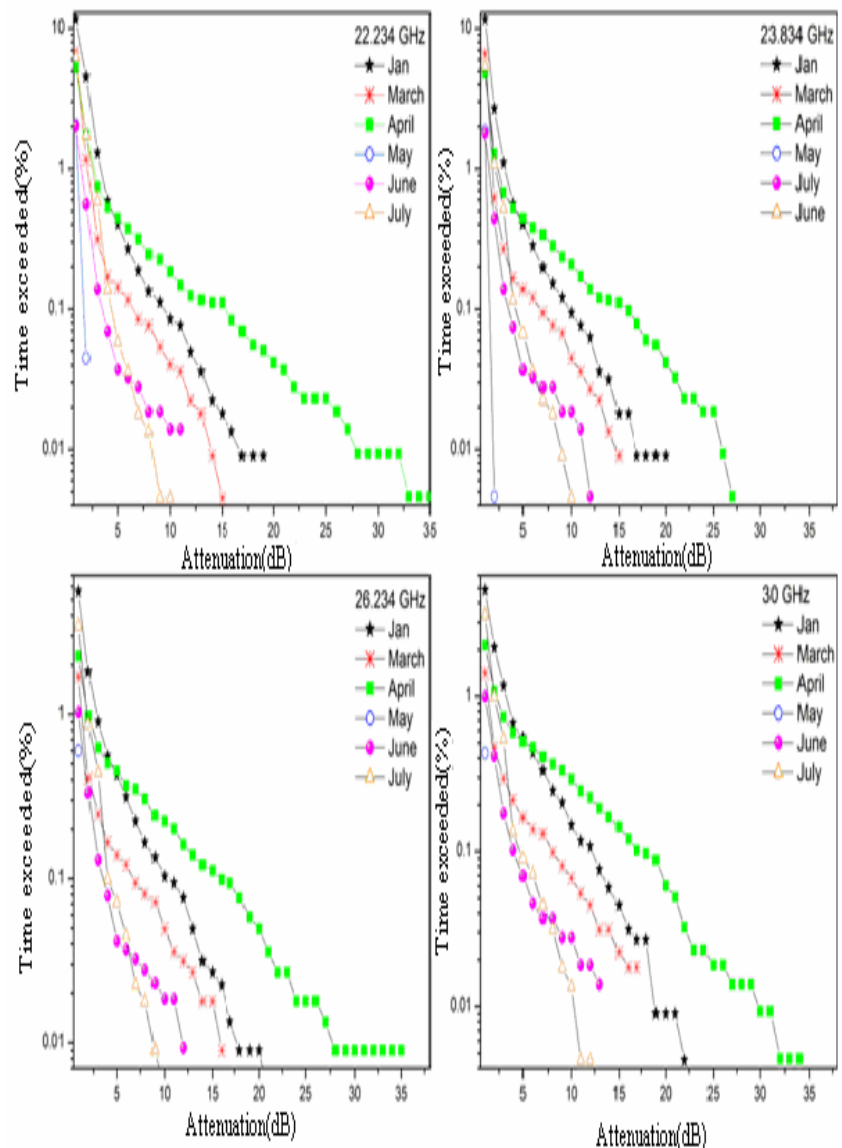

Fig 11 Monthly variation of attenuation time exceedence at different frequency

\section{REFERENCES}

Bebbington, D.H., Interference of drop size distribution functions from millimeter wave attenuation in rain IEE $3^{\text {rd }}$ conf. on AP, ICAP, 83, conf. Pub. pp. 219, 19-23, (1983)

CCIR, Radio meteorological data, Report 563, (1974).

CCIR, Attenuation by atmospheric gases, Rpt. 719(Mod. I), $\mathrm{V}(1982)$.

Davies, P.G., Propagation prediction at $\mathrm{mm}$ wavelengths, Presented at IEE colloquium on satellite communication above $18 \mathrm{GHz}$ on $20^{\text {th }}$ March 1987 digest no. 1987/34, (1987).

Devbarman, S.,1989, Significant heights for water vapour content in the atmosphere. International Journal of Remote Sensing, 10, pp. 1119-1124.

Fedi, F., Attenuation due to rain on a terrestrial path, Alta Frequenza, 48, no. 4, pp. 167-84, (April 1979).

Flavin, R.K. (1982), Rain attenuation considerations for sattelite paths in Australia, Australian Telecom. Research, 23(2), pp. 47-55.

Gibbins C.J., The effects of the atmosphere on radio wave propagation in the $50-70 \mathrm{GHz}$ frequency band, Journal of the Institution of Electronic and Radio Engineers, Vol. 58, No. 6 (supplement), pp. S229-S240, (1988).

Gibbins, C.J., D.G. Carter, P.A. Eggett, K.A. Lidiard, M.G. Pike, M.A. Tracey, E.H. White, J.M. Woodrofee, U.M. Yilmaz, A 500m experimental range for propagation studies at millimeter, infra-red and optical wavelengths, personal communication, (1986).

Gunn, K.L.S. and East, T.W.R., The microwave propagation of precipitation particles, Quart, Journal of Meteor, Sci. 80, pp. 522-545, (1954).

Harden, B.N., Norbury, J.R. and White, W.J.K., Estimation of attenuation by rain on terrestrial radio links in the U.K. at frequencies from 10 to $100 \mathrm{GHz}$, Microwave, optics and acoustics, Vol. 2, No. 4, (July 1978).

International Telecommunication Union (2003), Characteristics of precipitation for propagation modeling, Recommendation pp. 837-4, ITU-R Recommendation.

Joss, J., Thames, J.C. and Waldvogal, A., The variations of raindrop size distribution at Locarno, Proc. Intl Conf. on Cloud Physics, Toronto, Canada, (1968).

Karmakar, P.K., Studies on Microwave and Millimeter wave Propagation, Ph.D Thesis, University of Calcutta, WB, India, 1990.

Laws, J. O. and Parsons, D.A., The relation of raindrop size to intensity, Trans. Amer. Geophys. Union, 24, pp. 452-60, (1943). 
Liebe H.J., Takeshi Manabe, George A. Hufford, Millimeterwave attenuation and delay rates due to fog/cloud conditions, IEEE transactions on antennas and propagation, vol.37. no.12. (1989).

Lin, S.H., A method of calculating rain attenuation distribution in microwave paths, Bell Syst. Tech. J., Vol. 54, pp. 1051-1086, (1975).

Mandeep, J.S., and J.E. Allnutt (2007), Rain attenuation predictions at ku-band in South East Asia countries, Progress in Electromagnetic Research, 76, pp. 65-74.

Marshall, J.S. and Palmer, W. McK., The distribution of raindrops with size, J. Meteorol, 5, pp. 165-6, (1948).

Mie G., Contribution to the optics of suspended media, specifically colloidal metal suspensions, (in German) ann. Physik, 25, pp. 377-445, (1908).

Morison, J.A., Cross, M.J. and Chu, T.S., Rain induced differential attenuation and differential phase shift at microwave frequencies, ibid, Vol. 52, pp. 955-1020, (1974).

Norbury, J.R. and White, W.J.K., Meteorological magazine, vol. 104, pp. 221, (1975).

Oguchi, T. and Hosoya, Y., Scattering properties of oblate rain drops and cross-polarization of radiowaves due to rain. Part II; Calculations at microwave and millimeter wave regions, J. Radio Res. Labs (Japan), 21, pp. 151-259, (1974).

Olsen, R.L., Roggers, D.V. and Hodge, D.B., The $a R^{b}$ relation in calculation of rain attenuation, IEEE Trans. on antenna and Propagation, AP-26, pp. 318-29, (1978)

Ramchandran ,V., and V. Kumar(2007), Modified rain attenuation model for tropical regions for ku-band signals, International Journal of Satellite Communication and Networking, 25, pp. 53-67.

Ryde, J.W. and Ryde D., Attenuation of $\mathrm{cm}$ and $\mathrm{mm}$ waves by rain, hail, fog and clouds, G.E.C.R.L. Report 8670 , Weabley, England, (May 1945).

Sen, A.K., Karmakar, P.K., Das, T. K., Devgupta, A.K., Chakraborty, P.K., and Devbarman, S.,1989, Significant heights for water vapour content in the atmosphere. International Journal of Remote Sensing, 10, pp. 1119-1124.

Sen, A.K., Multifrequency radiometry and its applications, Project report of 'studies of Millimeter wave propagation by radio link and radiometer and system development' sponsored by Electronics Commission, Government of India, RPE-5, University of Calcutta, (April 1988).

Sinha, D.K., S.K. Chatterjee, P. Bandyopadhyay and D.K. Nath, Rain attenuation and fading on a line of sight microwave link, Indian J. Radio and Space Physics, vol. 16, Oct. 1987, pp. 360-63, (1987).

Ulaby, Microwave remote sensing, vol-1, (American Society of Photogrammetry), 1983,pp. 257-312.

Van de Hulst H.C., Light scattering by small particles, New York: Wiley, (1957). 